\title{
Unilateral Presentation of Pseudo-Kaposi's Secondary to Superficial Venous Insufficiency
}

\section{Aqil N*, Moustaide K, Gallouj S and Mernissi FZ}

Dermatologie, Centre Hospitalier Universitaire Hassan II, Morocco

*Corresponding author: Niema Aqil, Centre Hospitalier Universitaire Hassan II, Fès, Morocco, Email: niemaaqil90@gmail.com

\section{Case Report}

Volume 3 Issue 3

Received Date: October 25, 2018

Published Date: November 26, 2018

DOI: $10.23880 /$ cdoaj- 16000163

\section{Abstract}

Acroangiodermatitis is a benign uncommon vasoproliferative disorder that affects the lower extremities. It appears to be a reactive phenomenon related to severe chronic venous insufficiency and stasis of the lower extremities. The clinical presentation of this condition often is similar to Kaposi sarcoma. We report a case of acroangiodermatitis in a patient with superficial venous insufficiency.

Keywords: Acroangiodermatitis; Pseudo-Kaposi sarcoma; Superficial Venous Insufficiency; Genetic variants; Etiology

\section{Case Report}

A 58-year-old man without medical history, presented with multiple asymptomatic, firm, violaceous nodules and plaques distributed extensively over his right lower extremity.

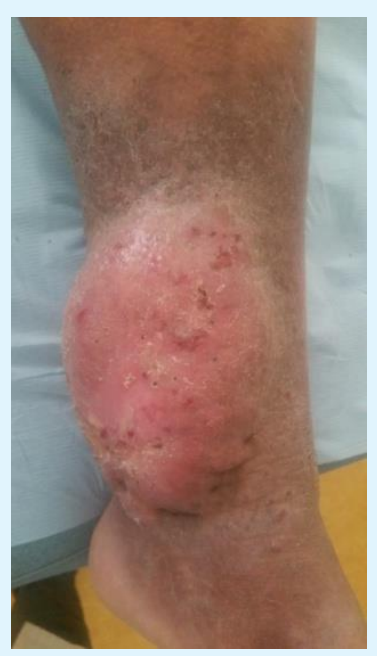

Figure 1: Clinical image of the violaceous tumor of the lower extremity.
The lesions developed approximately 6 years prior and gradually increased in number. A previous biopsy led to a diagnosis of hemangioma. Review of his clinical history did not reveal evidence of human immunodeficiency virus infection or Kaposi sarcoma. Physical examination revealed the presence of a violaceous tumor of $20 \mathrm{~cm}$, tender to palpation, infiltrated, with multiple $1-2 \mathrm{~cm}$ well-circumscribed, violaceous, scaly nodules extending from the right lower knee to the medial ankle (Figure 1).

The dermoscopy showed rainbow appearance (Figure 2 ). The examination of the surrounding skin shows hemosiderin deposition and chronic appearing vasculitis. There were multiple varicose veins evident on his lower extremities. All peripheral pulses were palpable. The rest of the physical examination was normal. Blood count and evaluation of serum glucose, renal and liver function were all normal. A Doppler ultrasound test detected superficial venous insufficiency of the right lower extremity. There was no failure of the deep venous system in the lower extremities or sonographic signs of thrombotic events, either in the superficial or deep venous systems. A biopsy specimen of the violaceous tumor was obtained. 
Histologic examination showed hyperplastic epidermis and demonstrated the presence of a proliferation in the dermis of small vessels with dilated light and lobulated disposition. These vessels are of regular size and contours, lined with a base of non-atypical endothelial cells sometimes surrounded by a layer of pericytes (Figure 3). This proliferation evolves on a fibrous and oedematous background of the dermis, which is strewed with many positive Perls heme pigments scattered over its entire height and even at the superficial hypodermis represented (Figure 4). The vessel walls were CD34 and negative for human herpes virus 8 . Acroangiodermatitis was diagnosed based on the clinical and histologic findings. The patient was prescribed compression stockings and Erythromycin. The patient was subsequently lost to follow-up.

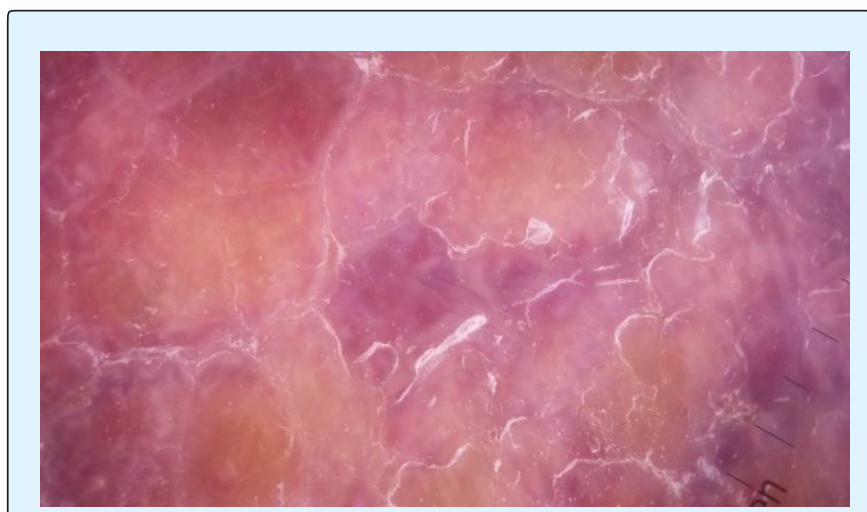

Figure 2: Dermoscopic image showing rainbow appearance.

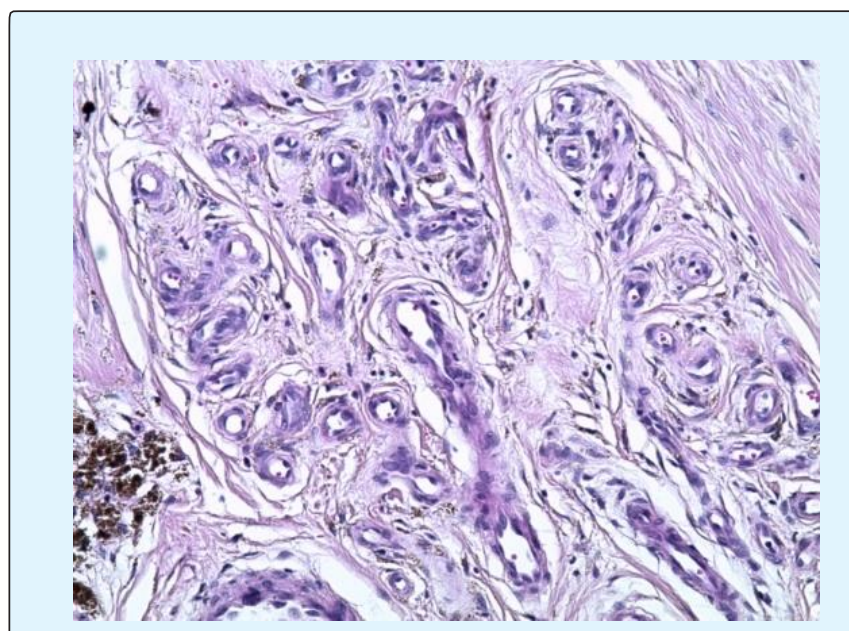

Figure 3: HES staining G x 200 -> Proliferation of capillary vessels with regular endothelium.

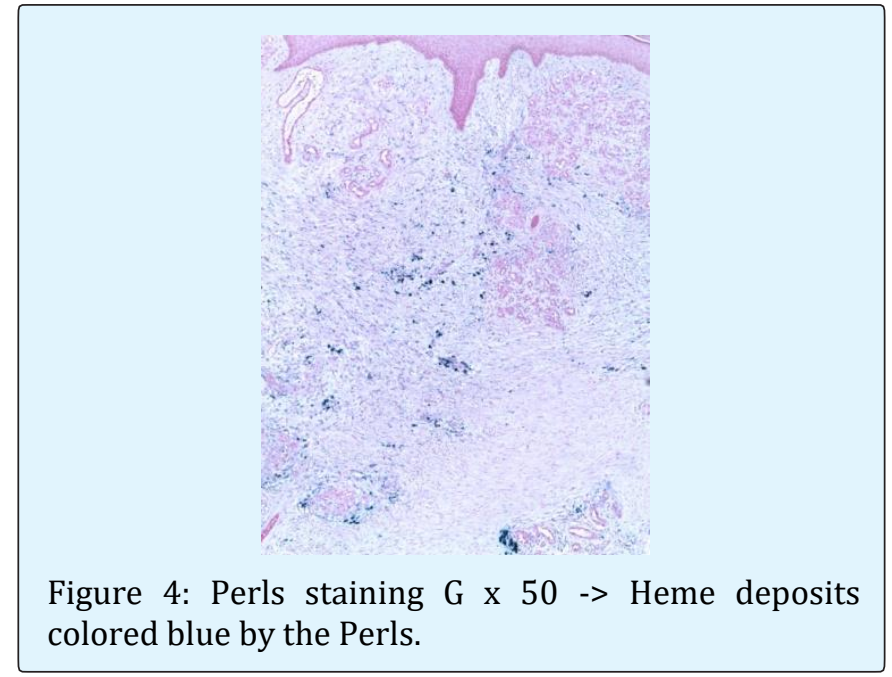

\section{Comments}

Acroangiodermatitis or pseudo-Kaposi's sarcoma can mimic several pathologies such as Kaposi's sarcoma, hemangioma, lymphangioma, lymphangiosarcoma, pigmented purpura, lichen aureus, vasculitis, lichen simplex chronicus and stasis dermatitis [1].

Histologically, there is an expansion of the entire capillary bed across the dermis. There are thick-walled and dilated capillaries showing reduplication that may indicate an angiomatous appearance. The endothelial cells lining these vessels are plump and CD 34 positive [2]. Some lesions may show nodular collections of narrowlumen vessels. There may be a mild perivascular fibroblastic proliferation. In addition to this, extravasated erythrocytes, spindle cells arranged horizontally, fibrosis, many accumulations of hemosiderin pigment may be present [3]. Its differential diagnosis with Kaposi sarcoma is important. Immunohistochemical staining with CD34 anti-serum helps to distinguish between acroangiodermatitis and Kaposi's sarcoma, since in the first there is an absence of perivascular CD34, unlike the latter (CD34 staining on the endothelial cells as well as the perivascular spindle cells) $[4,5]$.

Given its relative rarity, acroangiodermatitis is often misdiagnosed clinically $[1,6]$. The histopathological characteristics similar to Kaposi's sarcoma and other vascular tumors may also confuse professionals with little experience [5,6]. Misdiagnosis can lead to inadequate treatment, such as surgery, which often leads to complications [6]. Our patient remained undiagnosed for at least five years despite the examination of several 
physicians. An anterior biopsy for histopathology has been misinterpreted. Acroangiodermatitis lesions usually appear on the dorsal parts of the foot, especially on the big toe, as well as on the ankles and legs $[1,6]$ In the above case, the nature of the lesions was different with the presence of a huge tumor in the leg. The histopathologic and immunohistochemical tests carried out by an experienced pathologist were essential for achieving a correct diagnosis. Doppler ultrasound was also useful for determining the cause of the injury as chronic venous insufficiency (the so-called 'Mali syndrome') [7] Treatment of this condition has not been discussed in detail in the available literature, the mainstay of treatment being the correction of the underlying pathology. The use of compression bandages, stockings or pumps helps to relieve symptoms in case of underlying circulatory disorders. Various medical modalities of therapy have been tried with favourable results, but the options are limited. Oral erythromycin $500 \mathrm{mg}$ four times a day or dapsone $50 \mathrm{mg}$ twice a day for 3 months in combination with compression therapy has been tried with good results [8].

\section{Author's contribution}

All the authors contributed for the acquisition, analysis, interpretation of data for the work; and drafting the work or revising it critically for important intellectual content; and the final approval of the version to be published; and the agreement to be accountable for all aspects of the work in ensuring that questions related to the accuracy or integrity of any part of the work are appropriately investigated and resolved.

\section{References}

1. Rao B, Unis M, Poulos E (1994) Acroangiodermatitis A study of ten cases. Int J Dermatol 33(3): 179-181.

2. Weedon D, Vascular tumors (2010) Skin Pathology. $3^{\text {rd }}$ (Edn.), Printed in China: Chuchill Livingstone/Elsevier, pp: 910.

3. Ipek C, Kokenek-Unal TD, Alper M (2015) Spontaneous Acroangiodermatitis. Dermatology Round 60(3): 268-271.

4. Kanitakis J, Narvaes D, Claudy A (1996) Expression of the CD34 antigen distinguishes Kaposi's sarcoma from pseudo-Kaposi's sarcoma (acroangiodermatitis). Br J Dermatol 134(1): 44-46.

5. Azulay RD, Kac BK, Pereira GC, Cunha AFL (2004) Acroangiodermatite (pseudo-sarcoma de Kaposi). An Bras Dermatol 79(2): 193-197.

6. Hung NA, Strack M, Rij AV, North CJ, Blennerhassett JB (2004) Spontaneous acroangiodermatitis in a young woman. Dermatol Online J 10(2): 8.

7. Mali JWH, Kuiper JP, Hamers AA (1965) Acroangiodermatitis of the foot. Arch Dermatol 92: 515-518

8. Heller M, Karen JK, Fangman W (2007) Acroangiodermatitis. Dermatology Online Journal 13(1): 2. 